\title{
Extraordinarily preserved talpids (Mammalia, Lipotyphla) and the evolution of fossoriality
}

\author{
ACHIM H. SCHWERMANN ${ }^{1^{*}}$ and RICHARD S. THOMPSON ${ }^{2+}$ \\ ${ }^{1}$ Steinmann-Institut für Geologie, Mineralogie und Paläontologie, Rheinische Friedrich-Wilhelms- \\ Universität Bonn, Nussallee 8, 53115 Bonn, Germany, achim.schwermann@uni-bonn.de; \\ ${ }^{2}$ University Museum of Zoology, The University of Cambridge, Downing Street, Cambridge, CB2 3EJ, \\ United Kingdom, rst32@cam.ac.uk
}

Journal of Vertebrate Paleontology

\footnotetext{
${ }^{*}$ Corresponding author

${ }^{\dagger}$ Both authors should be contributed equally to this work, and consider this a joint first-authorship manuscript.
} 


\section{Character List}

Here we include the complete Sánchez-Villagra et al. (2006) character list, excluding those three characters that were modified. These are detailed later, followed by the new characters added for this study. The original comments on the characters and their scoring are removed for brevity, but can be easily accessed in the original article at:

\section{http://onlinelibrary.wiley.com/doi/10.1111/j.1096-0031.2006.00087.x/abstract}

Note: An asterisk "*" indicates the character is additive or ordered. Some citations include "char. XX" to specify the character number used by the original authors to refer to the same or similar feature.

\section{Dental characters}

1. First lower incisor i1: 0 = absent; $1=$ present.

2. Third upper incisor I3: 0 = absent; 1 = present.

3. Third lower incisor i3: 0 = absent; 1 = present.

4. Upper dP1: 0 = absent; 1 = present.

5. Lower dp1: 0 = absent; 1 = present.

6. Upper P2: 0 = absent; 1 = present.

7. Lower p2: 0 = absent; 1 = present.

8. Upper P3: 0 = absent; 1 = present.

9. Upper P3, number of roots: 0 = single-rooted; 1 = two or more roots.

10. Relative size (height and width) of first upper incisor and canine: $0=$ first upper incisor larger; $1=$ canine larger.

11. Upper P4, number of roots*: $0=1$ root; $1=2$ roots; $2=3$ roots. The following taxa were coded following Hutchison (1968, p. 20, table 2): Scaptonyx, Talpa europaea, Scaptochirus, Urotrichus, Neurotrichus, Scapanulus, Parascalops, Scalopus, Scapanus, Condylura.

12. Upper canine $\mathrm{C}: 0=$ absent; 1 = present.

13. Upper canine $C$, number of roots: $0=1$ root; $1=2$ roots.

14. Second upper molar $M 2$, relative height of buccal cusps: $0=$ metacone $>$ paracone; $1=$ subequal or paracone $>$ metacone.

15. Upper canine caniniform, with single posterior crest: $0=$ posterior crest absent; $1=$ posterior crest present.

16. Upper first molar M1, metacone is expanded posterolingually and approaches the position and function of a hypocone (Van Valen, 1967): 0 = not; 1 = yes.

17. Upper M2, distinct paraconule: 0 = absent; 1 = present 
18. Upper M2, distinct metaconule: 0 = absent; 1 = present.

19. First upper molar M1, mesostyle: 0 = absent; 1 = just one mesostyle visible; 2 = two mesostyles close to each other; 3 = two mesostyles separated by deep valley.

20. Second upper molar M2, mesostyle: 0 = absent; 1 = just one mesostyle visible; 2 = two mesostyles close to each other; 3 = two mesostyles separated by deep valley.

21. Second upper molar M2, relative length of metacrista and paracrista: $0=$ metacrista longer than paracrista; 1 = subequal.

22. "Anterior accessory cuspid (acc)" (Fig. 9; Hutchison, 1968, fig. 6) or in other words, small mesial (anterior) discrete shelf (additional cuspule) to paraconid in lower $\mathrm{m} 2$ : $0=$ absent; $1=$ present.

23. Distinctive anterior cingulum in lower molars m1-m2: $0=$ absent; $1=$ present.

24. Relative height of entoconid/metaconid in $\mathrm{m} 1: 0=$ metaconid $>$ entoconid; $1=$ subequal.

25. Talonid notch in $\mathrm{m} 1 / \mathrm{m} 2: 0$ absent; 1 = present.

26. Cristid obliqua in $\mathrm{m} 2: 0=$ separated from posterior wall of trigonid by a notch; $1=$ connected to posterior wall of the trigonid.

27. Teeth red-tipped when unworn: $0=$ no; 1 = yes.

28. Premolar row, when more than one upper premolar present (modified from Motokawa, 2004; char. 19): 0 = crowded; 1 = gapped.

29. Contact of second upper incisor with first incisor (based on Motokawa, 2004, char. 22): $0=$ absent; 1 = present.

30. Height of the upper canine in contrast to that of the first incisor (modified from Motokawa, 2004, char. 24)*: 0 = UC shorter than first incisor; 1 = subequal; 2 = taller.

31. Crown length versus width of the upper canine (based on Motokawa, 2004, char. 25): $0=$ subequal; 1 = crown length greater.

32. Crown height of the fourth upper premolar versus that of the upper canine (based on Motokawa, 2004, char. 26)*: 0 = fourth upper molar shorter; 1 = subequal; 2 = fourth upper molar taller.

33. Crown length versus width of the fourth upper premolar (based on Motokawa, 2004, char. 27): $0=$ length greater or subequal; 1 = length smaller than width.

34. The parastyle of the fourth upper premolar (based on Motokawa, 2004, char. 28): $0=$ obvious; $1=$ inconspicuous.

35. The crown length of the second upper molar versus that of the first molar (based on Motokawa, 2004, char. 31): 0 = subequal; 1 = smaller in the second upper molar.

36. Crown length of third upper molar versus that of the first molar (based on Motokawa, 2004, char. 32): $0=$ crown length of the third upper molar more than half than that of the first molar; $1=$ less than half. 
37. Crown area of third upper molar versus that of the fourth premolar (based on Motokawa, 2004, char. 33): $0=$ area of third upper molar subequal or larger; 1 = area of third upper molar smaller.

38. The metacingulum of the second upper molar (based on Motokawa, 2004, char. 38 ): $0=$ present; $1=$ absent.

39. Posterior cingulum cusp of the second lower incisor (based on Motokawa, 2004, char. 41): $0=$ present; 1 = absent.

40. Anterior cingulum cusp of the fourth lower premolar (based on Motokawa, 2004, char. 42): $0=$ present; 1 = absent.

41. Posterior cingulum cusp of the fourth lower premolar (based on Motokawa, 2004, char. 43): $0=$ present; 1 = absent.

42. Lower premolar teeth (modified from Motokawa, 2004, char. 44): $0=$ crowded; 1 = gapped.

43. Crown length of the first lower molar versus, that of the fourth premolar (based on Motokawa, 2004, char. 45)*: 0 = subequal; 1 = greater in first lower molar; 2 = much greater (more than twofold).

44. Crown length of second lower molar versus that of first molar (based on Motokawa, 2004, char. 47)*: $0=$ smaller in second lower molar; 1 = subequal; 2 = greater in second lower molar.

45. Crown length of third lower molar versus that of first molar (based on Motokawa, 2004, char. 48)*: 0 $=$ much smaller and minute in third lower molar; 1 = subequal or smaller third lower molar; 2 = greater third lower molar.

46. Metastylid of second lower molar (based on Motokawa, 2004, char. 49; see also Hutchison, 1968, table 2, p. 20, fig. 6): 0 = absent; 1 = present.

47. Trigonid and talonid width of second lower molar: $0=$ trigonid and talonid width subequal; $1=$ trigonid width greater than talonid width.

\section{Cranial characters}

48. Anterior nasal tip in lateral view (based on Motokawa, 2004, char. 1)*: $0=$ reaches the level of the incisors; 1 = the level of the canines; 2 = posterior to the posterior margin of the canines. Coding for Scaptochirus is 0 (contra Motokawa, 2004).

49. The anterior extremity of the incisive foramen (based on Motokawa, 2004, char. 2)*: $0=$ anterior to the anterior margin of the second incisor; $1=$ the level of the second incisor; $2=$ reaches the level of the third incisor or posterior.

50. The anterior extremity of the palatine foramen (modified from Motokawa, 2004, char. 3)*: $0=$ reaches level of P4; 1 = reaches level of first molar; 2 = reaches level of second molar.

51. Posterior margin of the anterior root of the zygomatic arch in ventral view ("anterior margin of the orbital region" of Motokawa, 2004, char. 5; wording modified same coding): 0 = extends to the second molar; 1 = extends to the third molar.

52. Zygomatic arch: 0 = absent; 1 = present.

53. Zygomatic arch (modified from Motokawa, 2004, char. 6): $0=$ shallow; $1=$ deep (its height exceeds half the cranial height at a given position). 
54. Lateral view of the zygomatic arch (modified from Motokawa, 2004, char. 8): $0=$ curved upwards; $1=$ straight or slightly curved downwards.

55. In dorsal view, location of contact of zygomatic arch with braincase (based on Motokawa, 2004, char. 10): $0=$ lateral portion of the anterior margin of the braincase; $1=$ medial to or at the middle point of the anterior margin of the braincase.

56. The anterior face of the zygomatic arch (modified from Motokawa, 2004, char. 12)*: $0=$ extends to the first molar level; 1 = extends to second molar; 2 = extends to the third molar level; $3=$ positioned posterior to the posterior margin or the third molar.

57. Position of posterior extremity of the auditory bulla in ventral view (based on Motokawa, 2004, char. $15)^{*}: 0=$ anterior to the anterior process of "mastoid process" (Motokawa, 2004); $1=$ in a similar position; 2 = posterior.

58. Anterior projection of mastoid ("mastoid process" sensu Motokawa, 2004) (modified from Motokawa, 2004, char. 17): 0 = well developed, projecting laterally; 1 = weakly developed or absent.

59. Dentary, upper sigmoid notch extension (based on Motokawa, 2004, char. 51): $0=$ upwards to the midline, between the uppermost portion of the lower base of the mandible and coronoid tip; $1=$ subequal to that level.

60. The posterior tip of the angular process of the dentary (based on Motokawa, 2004, char. 52)*: $0=$ anterior to the condyle; 1 = similar; 2 = posterior to the condyle.

61. Position of the mandibular condyle (based on Motokawa, 2004, char. 54)*: $0=$ below midline; $1=$ midline, between the upper sigmoid notch and the coronoid tip; 2 = upwards towards the coronoid process.

62. Relative position of lacrimal foramen relative to infraorbital foramen: $0=$ posterior to infraorbital foramen; 1 = just dorsal or dorsal at the level of the middle portion of infraorbital canal; $2=$ dorsal, just anterior to anterior border of infraorbital canal.

63. Foramina incisiva (sensu Koppers, 1990): 0 = small, antero-posterior length shorter than length of M2; 1 = hypertrophied, antero-posterior length equal or longer than added length of two last upper molars.

64. Foramen "I" (Koppers, 1990) in maxillare or in premaxillare-maxillare suture. 0 = absent; 1 = present.

65. Number of mental foramina, buccal side of dentary*: 0 = one; $1=$ two; 2 = three of more.

66. Mandibular angular process: $0=$ rod-like; $1=$ plate; $2=$ knob.

67. Anterior process of "mastoid process" $* 0=$ above root of zygomatic arch; $1=$ in line with root; $2=$ below root of zygomatic arch.

68. Relative position of posterior border of infraorbital foramen to upper molar row*: $0=$ anterior to or at border M1-M2; 1 = above, somewhere in M2 of border M2-M3; 2 = above, posterior to border M2M3.

69. Relative position of anterior border (internal side) of zygomatic arch to upper molar row*: $0=$ above, anterior to posterior end of $\mathrm{M} 2 ; 1=$ above, between border $\mathrm{M} 2-\mathrm{M} 3$ and posterior end of $\mathrm{M} 3 ; 2=$ above, posterior to M3. 
70. Height of M1 crown at buccal side/dentary height in adults without much wear in their teeth: $0=$ ratio typically below $1,1=$ ratio above 1 .

71. Fenestra ovalis shape: $0=$ maximal $/$ minimal diameter less than $2.5 ; 1=$ maximal $/$ minimal diameter more than 2.5

72. Stapes footplate: 0 = not bullate; 1 = bullate (sensu Sánchez-Villagra and Nummela, 2001).

73. Bony canal surrounding stapedial artery traversing the stapedial foramen: $0=$ absent; $1=$ canal partially or totally ossified

\section{Postcranial characters: shoulder region}

74. Clavicle: 0 = elongated, in some cases with strong processes directed medio-ventrally; $1=$ semirectangular, stout; 2 = quadratic (length $\mathrm{c} .=$ width) .

75. Clavicle, "foramen for vein" (Campbell, 1939, p. 5, figs 11-20): 0 = absent; 1 = present.

76. Clavicle, articulations*: $0=$ with scapula; $1=$ with scapula and humerus; $2=$ with just humerus.

77. Tetrahedral heterotopic bone wedged in between the ventromedial spine of the clavicle and anterior basilateral portion of the manubrium" (Hutchison 1968, p. 21): $0=$ absent; $1=$ present.

78. Scapula, suprascapular canal through the base of acromium (see Campbell, 1939, figs 27-29): $0=$ absent; 1 = present.

79. Scapula, infraspinous fossa (following Campbell, 1939; see also Reed, 1951): 0 = absent; 1 = present.

80. Scapula, marked teres fossa (see Sánchez-Villagra et al. 2006, fig. 5; Campbell, 1939, figs 22-31): 0 = absent; 1 = present.

81. Scapula, metacromium*: 0 = absent; 1 = present, small (length less than $1 / 3$ length of the total spine); 2 = present, large (length equal or more than $1 / 3$ length of the total spine).

82. Scapula, coracoid process (= metacoracoid, Klima, 1987) forms a distinctive process: $0=$ does not form conspicuous process; 1 = conspicuous process.

83. Sternum, ventral surface: $0=$ absence of distinct ridge; $1=$ distinct ridge does not form a keel; $2=$ prominent keel.

84. Sternum, proportions of manubrium*: $0=$ manubrial length/width less than $1.5 ; 1=$ between 1.5 and $3 ; 2=$ between 3.0 and $4.5 ; 3=$ more than 4.5 .

\section{Postcranial characters: vertebral column}

85. Axis and C3, relation of neural spines: 0 = not ankylosed; 1 = ankylosed dorsally.

86. Axis, neural spine: 0 = simple knob; 1 = keel with cranio-caudal orientation.

87. C6 transverse process posterior extension (Horovitz and Sánchez-Villagra, 2003, char. 19): $0=$ does not reach border C7-T1; 1 = reaches or surpasses border C7-TI.

88. Number of caudal vertebrae*: $0=$ equal or less than $14 ; 1=$ more than 14 , less than $20 ; 2=20$ or more. 


\section{Humeral characters}

89. "Deltoid process: 0 = absent; $1=$ present as flange distal to the greater tuberosity; $2=$ present as elongate hook on lateral edge of greater tuberosity.

90. "Position of humeral head: $0=$ on posterior to posteromedial side of proximal end; $1=$ lateral edge to center of head in line with lateral edge of shaft; 2 = medial edge of head in line with lateral edge of shaft; $3=$ entire head lateral to lateral edge of shaft" (Sánchez-Villagra et al., 2004, char. 2).

91. "Orientation of humeral head: $0=$ long axis of head parallel or subparallel to long axis of shaft; $1=$ long axis of head at oblique angle to long axis of shaft" (Sánchez-Villagra et al., 2004, char. 3).

92. "Minimum width of humerus*: $0=$ approximately $1 / 9-1 / 10$ th of the maximum length of humerus; $1=$ approximately $1 / 7$ th; 2 = approximately $1 / 4-1 / 5$ th; $3=$ approximately $1 / 3$ rd or less.

93. This character is modified in this study. See sections entitled 'Modified characters' below for details.

94. "Proximity of pectoral crest to lesser tuberosity: 0 = clear gap with a low proximal end of pectoral process; 1 = narrow gap or fused to form a bicipital tunnel.

95. "Floor of bicipital groove: 0 = straight and parallel to long axis of humerus; $1=$ displaced medially by pectoral crest near proximal end of humerus" (Sánchez-Villagra et al., 2004, char. 7).

96. "Open portion of proximal half of bicipital groove: $0=$ visible in anterior view; $1=$ visible in posterior view; 2 = not visible" (Sánchez-Villagra et at, 2004, char. 8).

97. "Pit for M. flexor digitorum profundus: 0 =absent, 1 = present" (Sánchez-Villagra et al., 2004, char. 10).

98. "Medial edge of trochlea: 0 = sharp, ventrally projecting ridge; 1 = straight or low ridge" (SánchezVillagra et al., 2004, char. 11).

99. "Lateral epicondyle: 0 = present as rounded protuberance; 1 = distal end forms laterally extended flange; 2 = lateral end has proximally directed hook; 3 = lateral end has spine-like proximally pointed hook" (Sánchez-Villagra et al., 2004, char. 12).

100. "Brachial fossa: 0 = small pit; 1 = cavernous excavation underlying greater tuberosity" (SánchezVillagra et al., 2004, char. 13).

101. "Crest between greater tuberosity and distal end of pectoral ridge: $0=$ present; $1=$ absent" (Sánchez-Villagra et al., 2004, char. 14).

102. "Trough between head of humerus and greater tuberosity: $0=$ no groove/very shallow; $1=$ deep groove" (Sánchez-Villagra et al., 2004, char. 15).

103. This character is modified in this study. See sections entitled 'Modified characters' below for details.

104. "Head of humerus: 0 = round; 1 = elliptical.

105. "Medial epicondyle builds proximally elongated flange or process: $0=$ absent; $1=$ present" (Sánchez-Villagra et al., 2004, char. 18).

106. "Greatest length of greater tuberosity and deltoid process: $0=$ relatively short, approximately $<1 / 4$ length of humerus; 1 = relatively long" (Sánchez-Villagra et al., 2004, char. 19). 
107. "Pectoral crest: 0 = single straight process parallel to long axis of humerus; $1=$ forms single curved process; 2 = long axis of humerus and pectoral crest having a perpendicular orientation (approximately 90)" (Sánchez-Villagra et al., 2004, char. 20).

108. "Clavicular facet: 0 = absent; 1 = in lateral view wedge-shaped; $2=$ rectangular; 3 = sharp ending" (Sánchez-Villagra et al., 2004, char. 26).

109. "Lateral side of capitulum: 0 = not noticeably elongated; 1 = laterally elongated so that capitulum has "football" shape" (Sánchez-Villagra et al., 2004, char. 28).

\section{Hand characters}

110. "Prepollex*: 0 = absent; 1 = present, just a knob; 2 = present, elongated, extending all along the scaphoid, but does not reach first metatarsal; 3 = present, extends to proximal portion of first metatarsal or beyond (os falciforme).

111. "Scaphoid and lunate*: 0 = not fused; 1 = fused: suture visible; 2 = fused, suture not visible.

112. "Triquetrum, ulno-palmar expansion originating from distal portion: $0=$ absent; 1 = present" (Sánchez-Villagra and Menke, 2005, char. 3).

113. "Small sesamoid lateral to triquetrum: 0 = absent; 1 = present" (Sánchez-Villagra and Menke, 2005, char. 4).

114. "Trapezium shape: 0 = distinctive distal arms absent; 1 = distinctive distal arms present. (SánchezVillagra and Menke, 2005, char. 5).

115. "Isolated centrale: 0 = absent; 1 = present. (Sánchez-Villagra and Menke, 2005, char. 6).

116. "Pisiform forms a plate larger in area than the triquetrum and palmar to triquetrum, hamate and ulna: 0 = no; 1 = yes (Sánchez-Villagra and Menke, 2005, char. 7).

\section{Pelvis and sacrum characters}

117. Fusion of acetabular area to vertebrae (Leche, 1883): $0=$ absent; $1=$ present.

118. Fusion of posterior horizontal branch of ischion to vertebrae* (Leche, 1883): $0=$ absent; $1=$ transverse processes expanded but not fused to ischion; 2 = fused.

119. This character is modified in this study. See sections entitled 'Modified characters' below for details.

120. Pubic symphysis in the shape of a narrow bridge (Leche, 1883): $0=$ absent; $1=$ present.

\section{Hindlimb characters}

121. Greater trochanter height: $0=$ level with or below femoral head; $1=$ higher than femoral head.

122. Third trochanter position: $0=$ more distal than lesser trochanter; $1=$ at the same level as lesser trochanter.

123. Tibial distal bridge (see Sánchez-Villagra et al. 2006, fig. 7, modified from Horovitz, 2004, char. 124): 0 = absent; 1 = present.

124. Tibial falciform process (Reed, 1951): $0=$ absent; $1=$ proximodistal blade; $2=$ actual laterally projecting falciform process. 
125. Fibular lateral process (Reed, 1951): $0=$ absent; $1=$ simple lateral process; $2=$ process with proximal head; $3=$ process with proximal and distal heads.

126. Fibular posterior process (Reed, 1951): $0=$ absent; $1=$ present.

127. Astragalus, process on lateral side of body: $0=$ absent; $1=$ present.

128. Astragalar head width (see Sánchez-Villagra et al. 2006, fig. 12): $0=$ narrower than body; 1 = as wide as body or wider.

129. Astragalar head, lateral side height relative to medial side: $0=$ equal; $1=$ lateral side higher.

130. Astragalar transverse ridge or groove posterior to trochlea: $0=$ absent; $1=$ ridge; $2=$ groove.

131. Astragalar posteroventral groove (for the flexor fibularis muscle, also known as flexor digitorum profundus, see Sánchez-Villagra et al. 2006, fig. 12): 0 = hallow groove; 1 = deep groove or canal.

132. Astragalar body shape* (see Sánchez-Villagra et al. 2006, fig. 12): $0=$ mediolaterally wider; $1=$ equal; 2 = anteroposteriorly longer.

133. Astragalar medial trochlear ridge orientation (see Sánchez-Villagra et al. 2006, fig. 12): $0=$ anteroposterior; 1 = posteriorly more lateral.

134. Anterior end of astragalar lateral trochlear ridge (modified from Horovitz, 2004, char. 141; see Sánchez-Villagra et al. 2006, fig. 12): 0 = lateral trochlear ridge ends on the anterior end of the body; $1=$ body is longer.

135. Astragalat medial plantar tuberosity (AMPT) protrudes medially beyond medial trochlear ridge (see Sánchez-Villagra et al. 2006, fig. 12): 0 = non-protruding; 1 = protruding.

136. Astragalar neck, angle with trochlea (see Sánchez-Villagra et al. 2006, fig. 12): $0=$ small angle; $1=$ large angle.

137. Astragalar posteroventral groove protrudes posteriorly in dorsal view: $0=$ non-protruding; $1=$ protruding.

138. Calcaneum sustentacular facet dimensions* (see Sánchez-Villagra et al. 2006, fig. 13): $0=$ mediolaterally larger; 1 = round to square; 2 = proximodistally longer.

139. Calcaneum peroneal process distal extent: $0=$ level with facet for cuboid; $1=$ protrudes distally.

140. Calcaneum peroneal process lateral extent (see Sánchez-Villagra et al. 2006, fig. 13): $0=$ does not protrude laterally; 1 = protrudes laterally.

141. Peroneal process position (see Sánchez-Villagra et al. 2006, fig. 13): $0=$ lateral to calcaneocuboid facet; 1 = dorsolateral to calcaneocuboid facet.

142. Calcaneum facet for cuboid, major axis*: $0=$ mediolaterally larger; $1=$ equal axes; $2=$ dorsoventrally larger; 3 = dorsoventrally much larger.

143. Ectal facet concave on tuber calcis: $0=$ absent; $1=$ present.

144. Peroneal process and sustentaculum proximodistal lengths (see Sánchez-Villagra et al. 2006, fig. 13): 0 = peroneal process shorter; 1 = equal or peroneal longer. 
145. Ectocuneiform medial canal: 0 = absent; 1 = present.

146. Navicular facet for astragalus*: $0=$ distal area larger; $1=$ medial and distal equal; $2=$ medial area larger.

147. Navicular ventral articular area size*: $0=$ absent; $1=$ ventral facet smaller than medial facet; $2=$ ventral and medial facets subequal.

148. Navicular shape in dorsal view: 0 = mediolaterally wider; 1 = proximodistally longer.

149. Cuboid medial proximal process (Horovitz, 2004, char. 172): $0=$ absent; $1=$ present.

150. Cuboid ventrolateral tunnel: $0=$ absent; $1=$ present

151. Cuboid proximal surface proximodistal location relative to that of the navicular: $0=$ equal; $1=$ cuboid surface more distal.

152. Prehallux in contact with entocuneiform and navicular (Sánchez-Villagra and Menke, 2005, fig. 8): 0 $=$ absent $; 1$ = present.

153. Length of Mt III relative to calcaneum*: $0=$ much longer, at least 1.31-fold as long as the calcaneum; $1=\mathrm{Mt}$ III between 1.16 and 1.01-fold longer; 2 = shorter than calcaneum.

154. Mt IV distal extent relative to Mt III: 0 = about equal; 1 = Mt IV extends beyond Mt III.

\section{Soft tissue characters}

155. Number of mammae*: $0=3$ pairs; $1=4$ pairs; $2=5$ pairs.

156. Position of nostrils (see Sánchez-Villagra et al. 2006, fig. 14): $0=$ anterior; $1=$ lateral; $2=$ superior

157. Tail: 0 = scaly; $1=$ not scaly.

\section{Modified characters}

Three characters from the Sánchez-Villagra et al. (2006) matrix were modified, as detailed below:

93. Distal end of pectoral crest: (0) does not form pronounced and distinct process (1) forms pronounced and distinct process oriented proximomedially (2) a small but prominent process protruding at right angles to the humeral shaft.

The distal end of the pectoral crest is generally smooth and flat in moles; however shrew-moles do have a distinct tubercle that sticks out prominently from the shaft at this point. We have added state 2 to account for this prominence, which is distinct from that seen in the Soricidae (see Sánchez-Villagra et al. (2004) for details).

103. Position of the lesser tuberosity relative to the proximal edge of the humeral head and the greater tuberosity: (0) inferior to the humeral head (1) level with the humeral head (2) superior to the humeral head and the greater tuberosity, forming a distinct notch in the proximal edge of the humerus between the greater and lesser tuberosities.

We have added state 2 to describe the notch which forms between the lesser tuberosity and humeral head due to the superior position of the lesser tuberosity in some taxa. Campbell (1939) noted this notch 
only in the Scalopini, though our observations suggest rather that the lesser tuberosity is elevated in the majority of taxa, excluding the Talpini and Uropsilus.

119. Pseudosymphysis of the pubis: (0) absent (1) pubes approach one another beneath the acetabulum, but do not quite touch (2) a pseudosymphysis is formed.

We have redefined character 119 to clarify that the pubic approach referred to by Sánchez-Villagra et al. (2006) is beneath the acetabulum, and in some taxa the pubes contact to form the pseudosymphsis of Reed (1951).

In addition to these character changes, we re-coded character 89 to correct the miscoding of SánchezVillagra et al. (2006), where state 1 appears as 0 , and state 2 as 1 in their matrix. This obviously has no effect on the analysis itself, but is rectified here for clarity and to aid interpretation.

\section{New characters}

The nineteen new characters introduced to the Sánchez-Villagra et al. (2006) are detailed below.

158. Form of the dorsal surface of the manubrium: (0) smooth (1) contains a well-defined trough (2) features a ridge, sometimes perforated by a foramen.

The dorsal surface of the manubrium varies widely in talpids, with most highly fossorial forms showing signs of the passage of a vein over the bone (Campbell, 1939). Most show a distinct trough in the manubrium, while Campbell noted the presence of a median ridge, permeated by a small foramen, indicating the presence of two blood vessels rather than one in Parascalops. This state was also noted in Scapanulus by Campbell (1939). Our own observations confirm this pattern, and recognise a similar ridged condition to a manubrium attributed to Domninoides mimicus in the collections of the AMNH (AMNH 74966).

159. Direction of the posterior end of the dorsal trough or ridge in the manubrium: (0) straight (1) deviates to the right side of the body posteriorly.

This is another characteristic of the dorsal manubrium noted by both Campbell (1939) and Hutchison (1968), and used in a cladistics analysis here for the first time. A groove which deviates to the right is seen in the Talpini.

160. Form of the scapula spine distal to the acromion: (0) smooth, beginning to taper away (1) a distinct tubercle or thickening of the spine (2) an elongate tubercle process.

In most taxa the scapula spine remains thin distal to the humerus. A number of talpids show a thickened tubercle towards the end of the spine, while others have an elongate spine or spindle-like process.

161. Form of the metacromion process of the scapula: (0) a relatively short, deltoid or amorphous projection (1) a more elongate process, often appearing 'spindle-like', with a distal terminal bulge.

The Sánchez-Villagra et al. (2006) analysis does account for the length of the metacromion relative to the length of the spine. Due to the length of the spine in many taxa, this does not fully capture the variation 
in form of the metacromion. A number of taxa have a thin metacromion which is shorter that $1 / 3$ of the spine's length.

162. Form of the clavicular facets: (0) facets are of a similar shape (1) the proximal and distal facets have different forms.

163. Angle of the clavicular facets from anterior view: (0) the facets are at different angles (1) near parallel facets.

164. Form of the ventral surface of the clavicle: (0) smooth, lacking a distinct process, though a notch may separate the proximal facet from the body of the clavicle (1) has a distinct ventral process.

165. Form of the ventral process of the clavicle: (0) the process is elongate and ventrally directed (1) the process is elongate and proximoventrally directed almost forming a closed tunnel on its ventral surface.

There is great variation in clavicular form within the Talpidae, and these characters aim to better capture this variation. The facets of the clavicle tend to be small and circular, a flattened more elongate semicircle, or large flat and ovoid. Semi-fossorial taxa tend to exhibit different clavicular facets at either end of the bone, while those ambulatory or highly fossorial forms show similar forms at each articulation. The most highly fossorial moles tend to have large flat and parallel facets on their stout claviculae.

The ventral processes of the clavicle are present in a number of groups and show some variation in their orientation. Talpins tend to exhibit a ventrally directed process, while shrew-moles, Parascalops and Scapanulus have more medially directed processes. There are no distinct processes in Scapanus and Scalopus, though this appears to be a consequence of the closure of the gap between the body and the ventral process: thus their absence is a product of secondary loss.

166. Form of the olecranon process of the ulna: (0) simple rod-like extension of the ulna, lacking any transverse processes (1) a distinct, transversely curved process (proximal process) is present, producing a broad triceps insertion.

The ulna was not an area addressed Sánchez-Villagra et al. (2006) analysis, yet it does show some distinct specialisations (see Hutchison, 1968) linked to fossoriality. A number of characters have been added here to attempt to trace their evolution, including the presence of a distinct lunate proximal process.

167. Ratio of the length of the olecranon process of the ulna to the length of the shaft: olecranon/shaft (0) $<0.4(1)>0.4$.

The states for this character are based on the presence of a break in the distribution of the ratios of all taxa in our sample (see Section 6 for details). No taxa fall between 0.33 and 0.48 . This neatly divides none fossorial and semi-fossorial forms from their highly fossorial relatives.

168. Form of the abductor fossa and posterior crest of the ulna: (0) the abductor fossa is narrow and the posterior crest is a weak ridge (1) the abductor fossa is deep, forming a thin plate of bone. It is laterally curved forming a pronounced posterior crest. 
169. Terminal process of the distal ulna (sensu Hutchison, 1968), defined as an elongate posteriorly projecting process on the distal ulna: (0) absent (1) present.

The presence of a large, posteriorly projecting terminal process is seen in a number of fossorial talpids, and correlates with the $90^{\circ}$ rotation of the manus.

170. Capitular process of the radius: (0) absent, or weak (1) present, a strong process that wraps around the distal end of the capitulum.

In many talpids the radius articulates with the lateral surface of the ulna, rather than the anterior edge. Its proximal end develops a long process posteriorly which curves around the capitulum of the humerus, strengthening the elbow joint and limiting its range of movement.

171. Scalopine ridge, running between the medial root of the humeral head and the distal margin of the lesser tuberosity: (0) absent or weak (1) present as a deep ridge.

This ridge runs from the distal root of the humeral head to the medial edge of the lesser tuberosity. Many talpids show a scar in this region, but others, notably those in the Scalopini, show a deep shelf or ridge. This is the Saclopine ridge of Campbell (1939).

172. Teres tubercle: (0) absent (1) present.

173. Form of teres tubercle on the medial surface of the humeral shaft: (0) a weak muscle scar (1) a distinct proximodistally short process (2) a distinct proximodistally elongate process.

Teres tubercle is seen in all talpids, but not all lipotyphlans. In non-talpids it tends to form a muscle scar, while most talpids have a proximodistally elongate and robust process. Notably both Uropsilus and Condylura have relatively short teres tubercles. Another variant, not scored here, is the tubercle of the desmans, which tends to lack the distinct proximal corner seen in other groups. This gives its tubercle a triangular rather than rectangular form.

174. Ratio of the maximum width across the metacarpals to the maximum length of the carpals and metacarpals (width/length): (0) $<1$ (1) $1<=x<1.5$ (2) $1.5<=x<2$ (3) $>2$. [Ordered]

This character describes the extent of the 'spade-like' adaptations of the talpid manus. Though the ratios produced do not cluster as well as those of the olecranon process, the categories used here do represent relatively distinct divisions in manus form (see Section 6 for details). The character is treated as ordered in the analysis due to the continual variation in manus size through the group.

175. Ratio of the width across the acetabulae to the width of the last lumbar centrum (centrum/acetabulum): (0) <=0.35 (1) >0.35.

The talpid pelvis is very narrow, with Reed (1951) suggesting that more fossorial forms show a narrower acetabular distance. Our data is less conclusive on this point (see Section 6 for details), with the only distinct break in the data separating the Desmanini, Uropsilus and outgroups from the other talpids. 
176. Form of the third trochanter of the femur: (0) a small, short flange (1) a short but broad and robust, hooked flange (2) an elongate flange running down the femoral shaft.

The desmans show an unusual broad hooked third trochanter, absent from other talpid groups. 


\section{Specimens observed}

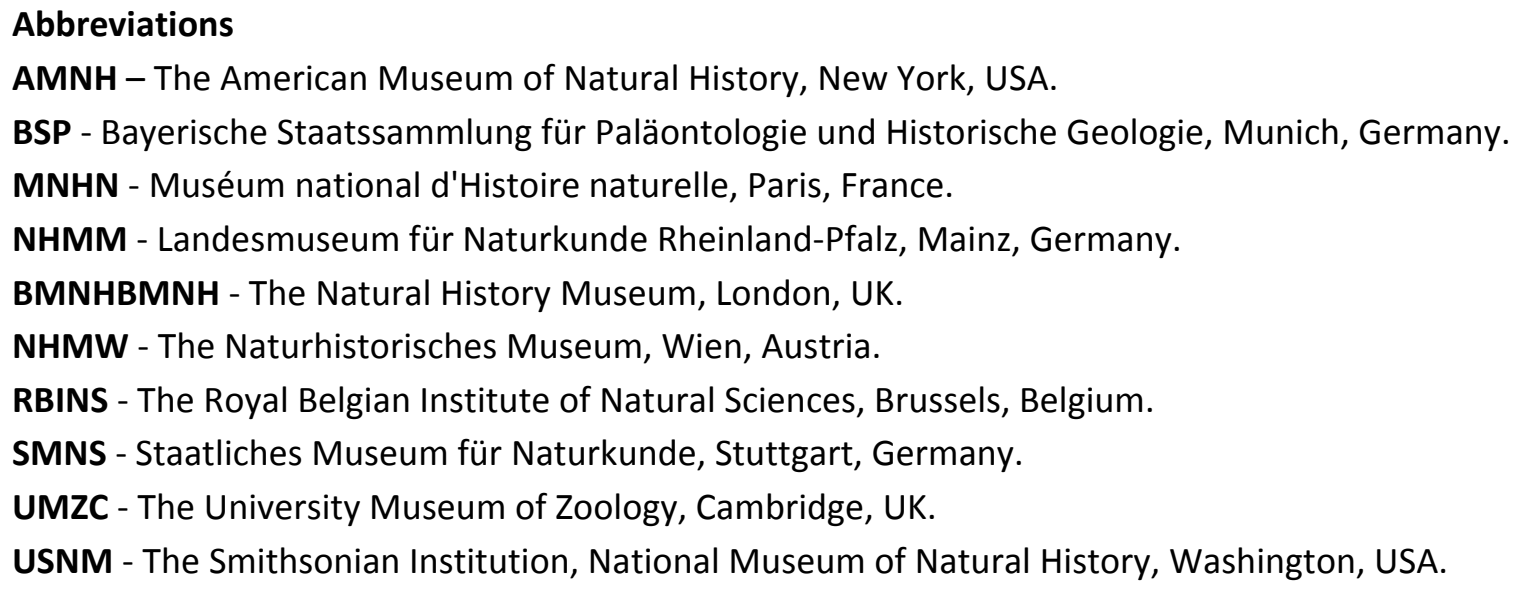

\section{Specimens observed}

\begin{tabular}{|c|c|c|c|}
\hline \multirow{2}{*}{ Erinaceus } & \multirow[t]{2}{*}{ europaeus } & $\mathrm{BMNH}$ & 2004.574 \\
\hline & & UMZC & E.5131.R, E.5131.Y, E.5130.B \\
\hline Solenodon & cubanus & UMZC & E.5418.B, E.5418.C \\
\hline \multirow[t]{2}{*}{ Crocidura } & \multirow[t]{2}{*}{ russula } & UMZC & E.5252.C \\
\hline & & $\mathrm{BMNH}$ & $1972.1786,1972.1787$ \\
\hline \multirow[t]{3}{*}{ Sorex } & \multirow[t]{2}{*}{ araneus } & UMZC & E.5190.H, E.5190.E \\
\hline & & $\mathrm{BMNH}$ & 2005.148 \\
\hline & minutus & UMZC & E.5192.C \\
\hline Blarina & brevicauda & $\mathrm{BMNH}$ & $85.939,85.938,1958.3 .11 .9,75.2016,75.2017$ \\
\hline \multirow[t]{3}{*}{ Uropsilus } & \multirow[t]{2}{*}{ soricipes } & BMNH & 11.9.8.12 \\
\hline & & USNM & $256119,574299,574300,574302$ \\
\hline & andersoni & $\mathrm{BMNH}$ & 11.2.1.31, 13.9.13.1 \\
\hline \multirow[t]{3}{*}{ Desmana } & \multirow[t]{3}{*}{ moschata } & UMZC & E.5292.A \\
\hline & & BMNH & 89.11 .12 .1 \\
\hline & & MNHN & 1959147 \\
\hline \multirow[t]{2}{*}{ Galemys } & \multirow[t]{2}{*}{ pyrenaicus } & $\mathrm{BMNH}$ & $60.599,60.602,1919.7 .7 .1784,1960.10 .11 .9$ \\
\hline & & MNHN & 1961752 \\
\hline \multirow[t]{3}{*}{ Scaptonyx } & \multirow[t]{3}{*}{ fusicaudus } & AMNH & 114562 \\
\hline & & $\mathrm{BMNH}$ & 32.11.1.17, 22.9.1.12, 32.11.1.16 \\
\hline & & USNM & 574303 \\
\hline \multirow[t]{2}{*}{ Talpa } & \multirow[t]{2}{*}{ europaea } & UMZC & E.5334.P, E.5334.H, E.5334.N \\
\hline & & $\mathrm{BMNH}$ & 51.558 \\
\hline \multirow[t]{2}{*}{ Scaptochirus } & \multirow[t]{2}{*}{ moschatus } & $\mathrm{BMNH}$ & 28.1.6.2, 28.1.6.2, 14.8.26.1, 16.1.1.4 \\
\hline & & USNM & 172578 \\
\hline \multirow[t]{3}{*}{ Euroscaptor } & klossi & $\mathrm{BMNH}$ & $62.712,1966.95 .335$ \\
\hline & micrura & BMNH & 16.3.25.36, 1890.1.1.1.1 \\
\hline & longirostris & BMNH & 11.2.1.24 \\
\hline Mogera & wogura & UMZC & E.5355.D, E.5355.B \\
\hline
\end{tabular}




\begin{tabular}{|c|c|c|c|}
\hline & & BMNH & 6.1.4.442, 25.9.3.29, 1854.4.29.2, 1997.135, 5.1.4.22 \\
\hline Parascaptor & leucura & $\begin{array}{l}\text { AMNH } \\
\text { BMNH }\end{array}$ & $\begin{array}{l}115556 \\
\text { 32.11.1.177, 21.7.6.8, 1951.11.12.9, 7.1.1.20a, 93.7.1.1, } \\
\text { 20.11.1.28 }\end{array}$ \\
\hline Urotrichus & talpoides & $\begin{array}{l}\text { UMZC } \\
\text { BMNH }\end{array}$ & $\begin{array}{l}\text { E.5328.D } \\
\text { 6.1.4.444, 66.2.23.6, 5.3.3.9, 5.3.3.4, 1966.7.6.1, } \\
\text { 1966.7.6.2 }\end{array}$ \\
\hline Dymecodon & pilirostris & BMNH & $8.2 .2 .5,8.12 .1 .36$ \\
\hline Neurotrichus & gibbsii & $\begin{array}{l}\text { UMZC } \\
\text { BMNH } \\
\text { MNHN } \\
\text { USNM }\end{array}$ & $\begin{array}{l}\text { E.5329.C } \\
\text { 7.7.7.3455, 7.7.7.3481 } \\
\text { CG2006 373, CG } 2006374 \\
561651\end{array}$ \\
\hline Scapanulus & oweni & $\begin{array}{l}\text { BMNH } \\
\text { USNM } \\
\text { AMNH }\end{array}$ & $\begin{array}{l}12.8 .5 .2 \\
240757 \\
56904\end{array}$ \\
\hline Parascalops & breweri & $\begin{array}{l}\text { NHMW } \\
\text { BMNH } \\
\text { USNM }\end{array}$ & $\begin{array}{l}62568,62569 \\
7.7 .7 .2426,95.1 .7 .5 \\
248541\end{array}$ \\
\hline Scalopus & aquaticus & $\begin{array}{l}\text { BMNH } \\
\text { BMNH } \\
\text { MNHN }\end{array}$ & $\begin{array}{l}\text { 29.11.7.11, 7.7.7.2812, 75.2019, 75.2020, 7.7.7.2815 } \\
\text { 1958.3.11.7 } \\
\text { CG2006 } 378\end{array}$ \\
\hline Scapanus & $\begin{array}{l}\text { townsendii } \\
\text { latimanus } \\
\text { orarius }\end{array}$ & $\begin{array}{l}\text { BMNH } \\
\text { USNM } \\
\text { MNHN } \\
\text { MNHN } \\
\text { USMN }\end{array}$ & $\begin{array}{l}7.7 .7 .374,7.7 .7 .375 \\
205052,205053 \\
\text { CG2006 } 379 \\
\text { CG2006 } 382 \\
557471\end{array}$ \\
\hline Condylura & cristata & $\begin{array}{l}\text { UMZC } \\
\text { BMNH } \\
\text { USNM }\end{array}$ & $\begin{array}{l}\text { E.5371.D } \\
92.12 .5 .3,1958.3 .11 .5,1958.3 .11 .6 \\
566403\end{array}$ \\
\hline Domninoides & mimicus & AMNH & 74996 \\
\hline Eotalpa & $\begin{array}{l}\text { anglica } \\
\text { belgica }\end{array}$ & $\begin{array}{l}\text { BMNH } \\
\text { RBINS }\end{array}$ & $\begin{array}{l}\text { M43076, M43077, M45350 } \\
\text { IRSNB M 1929-34 }\end{array}$ \\
\hline Geotrypus & $\begin{array}{l}\text { antiquus } \\
\text { montisasini }\end{array}$ & $\begin{array}{l}\text { NHMM } \\
\text { SMNS }\end{array}$ & $\begin{array}{l}\text { 1997/PW5145 } \\
44523,43499\end{array}$ \\
\hline Mygalea & jaegeri & BSP & 2008 LI280 \\
\hline Proscapanus & $\begin{array}{l}\text { sansaniensis } \\
\text { intercedens }\end{array}$ & $\begin{array}{l}\text { BSP } \\
\text { NHMW }\end{array}$ & $\begin{array}{l}2008 \text { LI282 } \\
1997 z 0165-002-1\end{array}$ \\
\hline
\end{tabular}




\section{Additional Analyses}

Figure $1 S$ shows the impact on the unconstrained phylogeny of including both species of Eotalpa without any on the other fossil taxa. This analysis was carried out in PAUP* v4.0 and followed the same analytical procedure as used in the main analysis.

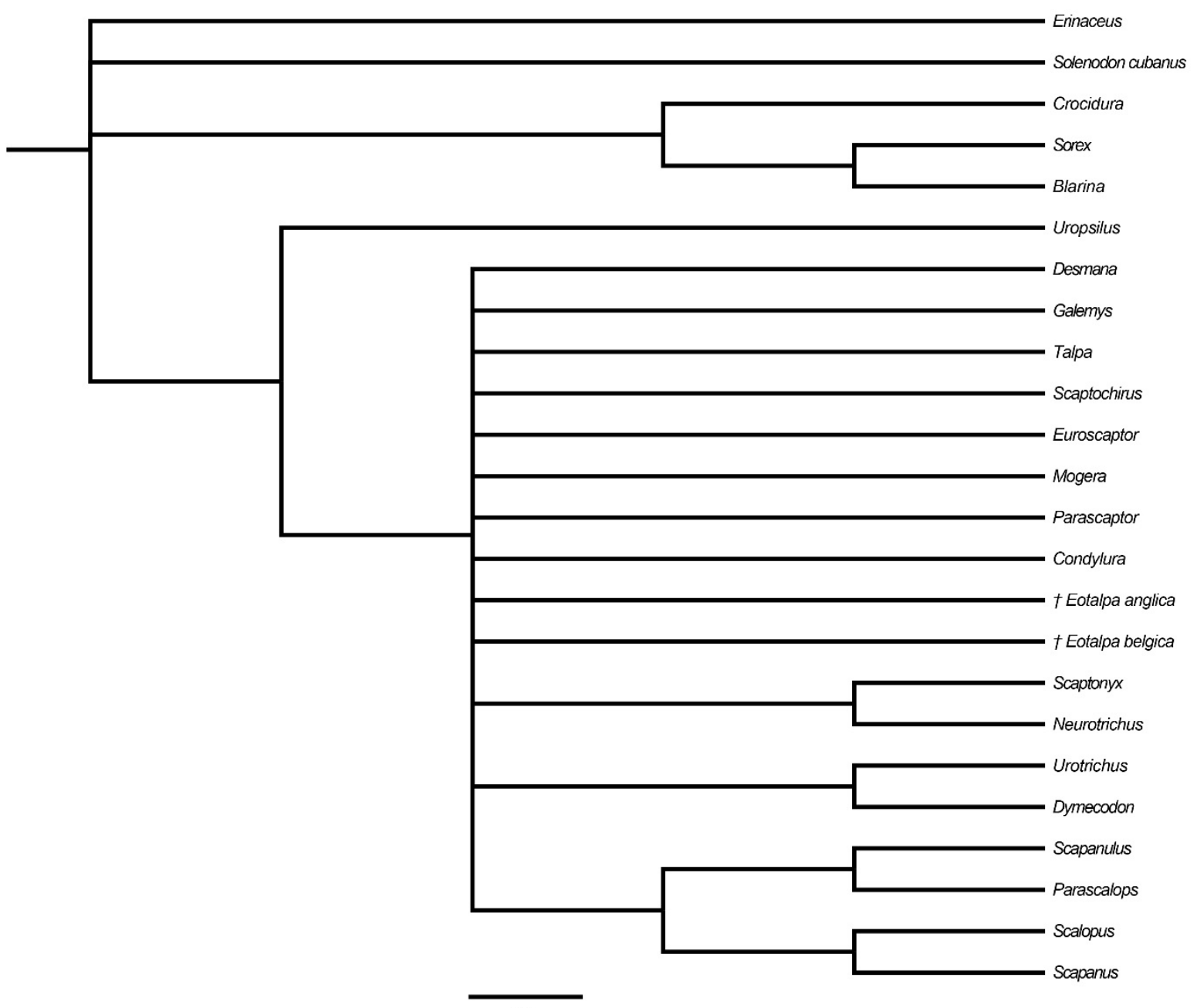

0.6

FIGURE 1S. Unconstrained phylogeny of both Eotalpa-species without any other fossil taxa. 


\section{Character Optimisations for the Geotrypus montisasini-Scalopini-Talpini trichotmy}

Table $2 S$ details a set of character state changes optimisations designed to help the interpretation of the placement of Geotrypus montisasini in the unconstrained analysis. The position of G. montisasini is varied as described in the table, and the characters uniting the specified clades unambiguously (Unamb.) or only under ACCTRAN and DELTRAN optimisations are recorded. Characters in red are not scored for $G$. montisasini. Those in blue are scored differently for $G$. monitisasini. Those in green are identical to the score for G. montisasini.

TABLE 2S. Character state changes for interpretation of the placement of Geotrypus montisasini.

\begin{tabular}{|c|c|c|c|}
\hline \multicolumn{4}{|c|}{ G. montisasini in a polytomy with Talpini and Scalopini } \\
\hline & Unamb. & ACCTRAN & DELTRAN \\
\hline Scalopini & $\begin{array}{l}\text { 78:1, 80:0, } \\
171: 1\end{array}$ & $\begin{array}{l}\text { 19:3, 20:3, 26:3, 29:0, } \\
\text { 48:0, 49:0, 57:2, 102:0, } \\
\text { 108:0, 132:1, 153:2 } \\
\text { 156:1, 171:1, 174:3 }\end{array}$ & $19: 3,22: 1,34: 1,92: 3,106: 1$ \\
\hline Talpini & $\begin{array}{l}10: 1,30: 2 \\
31: 1,32: 0\end{array}$ & $\begin{array}{l}\text { 34:0, 40:0, 67:1, 79:0, } \\
92: 2,114: 1,118: 0 \\
\text { 133:1, 159:1, 165:0 }\end{array}$ & $19: 2,20: 2,22: 1,106: 1$ \\
\hline \multicolumn{4}{|c|}{ G. montisasini is the sister group to Talpini } \\
\hline & Unamb. & ACCTRAN & DELTRAN \\
\hline Scalopini & $\begin{array}{l}\text { 78:1, 171:1, } \\
19: 3\end{array}$ & $\begin{array}{l}\text { 20:3, 29:0, 49:0, 102:0, } \\
\text { 108:2, 132:1, 153:2, } \\
\text { 156:1, 174:3 }\end{array}$ & $22: 1,34: 1,81: 0,92: 3,106: 1$ \\
\hline Talpini + G. mont. & - & $\begin{array}{l}10: 1,26: 1,30: 2,32: 0 \\
48: 1,67: 1,79: 0,114: 1 \\
\text { 118:0, 133:1, 159:1, } \\
165: 0\end{array}$ & - \\
\hline \multicolumn{4}{|c|}{ G. montisasini is the sister group to Scalopini } \\
\hline & Unamb. & ACCTRAN & DELTRAN \\
\hline Scalopini + G. mont. & $34: 1,92: 3$ & $\begin{array}{l}\text { 29:0, 40:1, 49:0, 108:2, } \\
\text { 132:1, 153:2, 156:1, } \\
\text { 161:0, 174:3 }\end{array}$ & $74: 2,164: 0$ \\
\hline Talpini & $\begin{array}{l}10: 1,30: 2 \\
31: 1,32: 0\end{array}$ & $\begin{array}{l}48: 1,67: 1,79: 0,114: 1 \\
\text { 118:0, 133:1, 159:1, } \\
165: 0\end{array}$ & $19: 2,20: 2,22: 1,106: 1$ \\
\hline
\end{tabular}




\section{The clavicle of Talpa europaea}

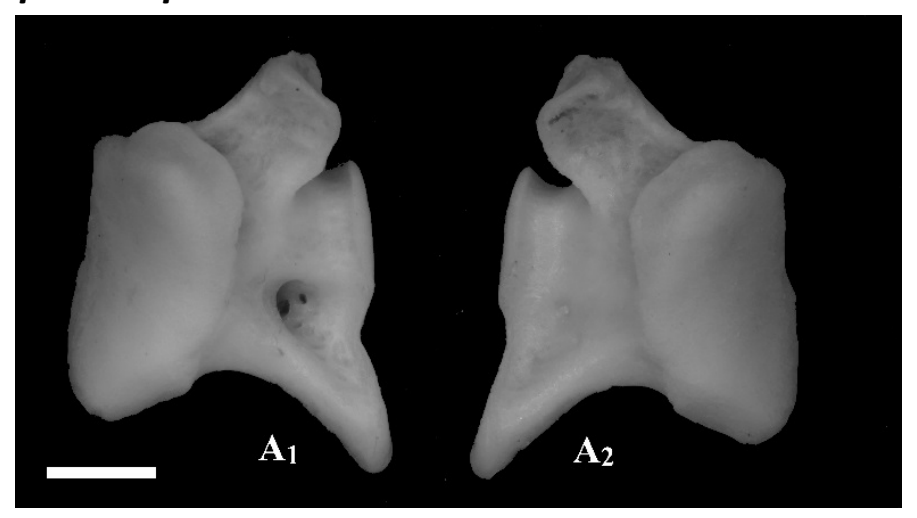

FIGURE 2S. Right $\left(A_{1}\right)$ and left $\left(A_{2}\right)$ claviculae of a single individual of Talpa europaea (StIPB M7089) from the collection of the palaeontological section at the Steinmann Institute in Bonn. This shows the welldeveloped foramen in the right clavicle, but no opening in the left one. Scale bar $=1 \mathrm{~mm}$. 


\section{Continuous character data}

Three of our additional characters are derrived from continuous measurements of variation throughout our taxon sample (fig 3S). These measures were all converted into ratios, before the values of the ratios were ploted on an axis. Character state boundaries were determined based on any distinct gaps in the distribution of the data. The distribution plots for the three characters in question are shown below, with the red arrows indicating the character boundaries.

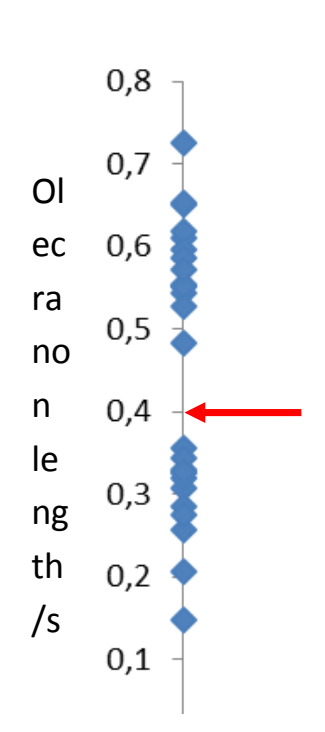

Character 167

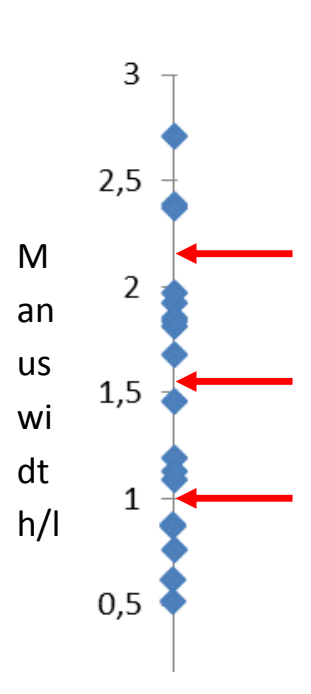

Character 174

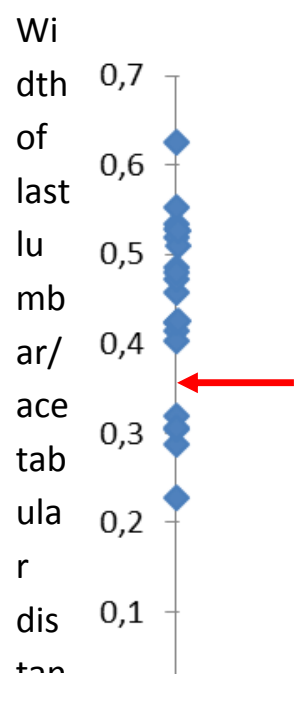

Character 175

FIGURE 3S. Three characters, which are derrived from continuous measurements.

For characters 167 and 175 there is a distinct gap in the distributions at their midpoint. These characters lend the selves to a binary distribution. Character 174 is less clear cut: division into 4 state based around simple to discern ratio values (1, 1.5 and 2$)$ does match the distribution well, with each number falling in, or at the edge of a distinct break in the data. 


\section{References}

Campbell, B. 1939. The shoulder anatomy of the moles. A study in phylogeny and adaptation. The American Journal of Anatomy 64:1-39.

Horovitz, I. 2004. Eutherian mammal systematics and the origins of South American ungulates as based on postcranial osteology. Bulletin of Carnegie Museum of Natural History:63-79.

Horovitz, I., and M. Sánchez-Villagr. 2003. A comprehensive analysis of marsupial higher-level relationships. Cladistics 19:181-212.

Hutchison, J. H. 1968. Fossil Talpidae (Insectivora, Mammalia) from the later Tertiary of Oregon. Bulletin of the Museum of Natural History, University of Oregon 11:1-117.

Koppers, D. 1990. Vergleichende anatomisch-systematische Untersuchungen an Schädeln von Talpa europaea und anderen Insectivoren. Zoologisches Jahrbuch der Anatomie 120:109-125.

Leche, W. 1883. Zur Anatomie der Beckenregion bei Insectivora, mit besonderer Berücksichtigung ihrer morphologischen Beziehungen zur derjenigen anderer Saugethiere. Kongl. Svenska VetenskapsAkademiens Handlingar sev. 4 20:1-113.

Motokawa, M. 2004. Phylogenetic relationshipa within the family Talpidae (Mammalia: Insectivora). Zoological Journal of the Linnean Society 263:147-157.

Reed, C. A. 1951. Locomotion and Appendicular Anatomy in three Soricoid Insectivores. The American Midland Naturalist 45:513-671.

Sánchez-Villagra, M. R., I. Horovitz, and M. Motokawa. 2006. A comprehensive morphological analysis of talpid moles (Mammalia) phylogenetic relationships. Cladistics 22:59-88.

Sánchez-Villagra, M. R., and P. R. Menke. 2005. The mole's thumb-evolution of the hand skeleton in talpids (Mammalia). Zoology 108:3-12.

Sánchez-Villagra, M. R., P. R. Menke, and J. H. Geisler. 2004. Patterns of evolutionary transformation in the humerus of moles (Talpidae, Mammalia): a character analysis. Mammal Study 29:163-170.

Valen, L. v. 1967. New Paleocene insectivores and insectivore classification. Bulletin American Museum of Natural History 135:217-284. 